CLINICAL STUDY

\title{
Influence of preterm birth and small birth size on serum anti-Müllerian hormone levels in young adult women
}

\author{
G F Kerkhof, R W J Leunissen, R H Willemsen, F H de Jong ${ }^{1}$, J A Visser ${ }^{1}$, J S E Laven ${ }^{2}$ and A C S Hokken-Koelega \\ Division of Endocrinology, Department of Pediatrics, Erasmus MC Sophia Children's Hospital, Room number: Sp-4478, Dr Molewaterplein 60, 3015 GJ \\ Rotterdam, The Netherlands, ${ }^{1}$ Division of Endocrinology, Department of Internal Medicine, Erasmus MC, PO Box 2040, 3000 CA Rotterdam, The \\ Netherlands and ${ }^{2}$ Division of Reproductive Medicine, Department of Obstetrics and Gynaecology, Erasmus MC, Dr Molewaterplein 40, 3015 GD \\ Rotterdam, The Netherlands
}

(Correspondence should be addressed to G F Kerkhof; Email: g.kerkhof@erasmusmc.nl)

\begin{abstract}
Background/objectives: Preterm birth has been associated with reduced reproduction rates, and controversies remain regarding the effect of being born small for gestational age (SGA) on ovarian function. Recent findings in young men showed no effect of preterm and SGA birth on testis function. We hypothesised that follicle pool size in young adult women is also not affected by preterm and SGA birth.

Design/methods: In 279 young women of the PROGRAM/PREMS study, aged 18-24 years, the influence of gestational age, birth length and birth weight on serum levels of anti-Müllerian hormone $(\mathrm{AMH})$ was analysed with multiple regression modelling. Additionally, AMH levels were analysed in preterm- versus term-born females and in three subgroups: females born SGA with either short stature or catch-up growth (SGA-CU), and females born term and appropriate for gestational age with normal stature (AGA controls).

Results: Preterm and SGA birth did not affect AMH and other hormone levels. Older age at menarche and oral contraceptive pill use (OC-use) were related to lower AMH levels, and maternal smoking during gestation was related to higher AMH levels. After correction for maternal smoking, lower socioeconomic status (SES) was associated with lower AMH levels. In subgroup comparisons, SGA-CU women showed higher AMH levels than AGA controls, also after adjustment for several factors.

Conclusion: Preterm and SGA birth did not affect AMH levels. Factors associated with serum AMH levels were OC-use, age at menarche, maternal smoking during gestation and SES. We conclude that preterm- and/or SGA-born females are not likely to have a reduced follicle pool size.
\end{abstract}

European Journal of Endocrinology 163 937-944

\section{Introduction}

Controversies exist regarding the association between preterm and small for gestational age (SGA) birth and abnormal ovarian function in adulthood. Some studies showed smaller ovaries and uterus in infant and adolescent women born SGA $(1,2)$. Others found no differences in ultrasonic measurements of the uterus and ovaries in girls born SGA (3); neither did intrauterine growth retardation (IUGR) affect the ovarian volume of fetuses nor the volume percentage of follicles in the ovaries (4).

With regard to the relationship between preterm birth and ovarian function, less research has been performed. Preterm birth might affect gonadal function, as reduced reproduction rates have been reported in men and women who had been born preterm (5). However, this lower reproduction rate in women could be a consequence of altered environmental factors related to socioeconomic status (SES), rather than reduced gonadal function, as has been demonstrated in men (6).

As a consequence of undernutrition causing altered programming of the fetus and SGA birth, one might expect a negative effect of SGA birth on gonadal function (7). However, we previously demonstrated that preterm and SGA birth did not affect inhibin B levels and other gonadal parameters in young men (6). In young women, the association between preterm and SGA birth and ovarian function has not been studied. Because we did not expect the influence of SGA and preterm birth in women to be different from that in men, we hypothesised that the size of the follicle pool in young adult women is not affected by preterm and/or SGA birth.

To test our hypothesis, we investigated the effects of gestational age at birth, birth weight (BW) SDS, birth length (BL) SDS and adult size on serum anti-Müllerian hormone (AMH), in a large group of 279 women aged 
18-24 years. AMH is correlated with the number of growing follicles and indirectly correlated with the primordial follicle pool (8). It is a marker of the follicle pool size, which decreases with age and is undetectable after menopause $(8,9)$. Most studies showed that $\mathrm{AMH}$ levels are independent of menstrual cycle (10-12), but controversies still exist (13).

In addition, serum AMH levels were investigated after dividing the total study population into women born either preterm or term and into three clinically relevant subgroups of young adult women: women with either a short or a normal stature born SGA, and a group of women with a normal stature born term and appropriate for gestational age (AGA controls).

\section{Subjects and methods}

\section{Subjects}

The PROGRAM/PREMS study cohort consists of 279 healthy female participants aged 18-24 years. The subjects who were asked to participate were selected using registration data from academic hospitals in the Netherlands. They were selected because of being born preterm (gestational age $<36$ weeks), being small at birth (SGA with a BL $<-2$ SDS) (14) or showing short stature (after being born SGA or AGA with an adult height $<-2$ SDS) (15). In addition, healthy subjects were randomly asked to participate as controls. They were randomly recruited by advertising in newspapers, public transport, schools with different educational levels, festivals, etc. to avoid selection bias. The participation rate of the PROGRAM/PREMS study cohort was $79.5 \%$ (6). All subjects fulfilled the same inclusion criteria age 18-24 years, born singleton, Caucasian, an uncomplicated neonatal period without signs of severe asphyxia (defined as an Apgar score below 3 after $5 \mathrm{~min}$ ), without sepsis or long-term complications of respiratory ventilation such as bronchopulmonary dysplasia, maximum duration of respiratory ventilation and/or oxygen supply in the neonatal period of 2 weeks. Subjects were excluded if they suffered or had suffered from any serious condition (including heart, lung, neurological, gastrointestinal and kidney disease), serious complication (including necrotizing enterocolitis, intraventricular haemorrhage with a degree of three or more, spastic hemiplegia or quadriplegia) or had been subjected to any condition or treatment known to interfere with growth (e.g. GH treatment, treatment with glucocorticosteroids, radiotherapy, GH deficiency, severe chronic illness, emotional deprivation), or if they had endocrine or metabolic disorders, chromosomal defects, syndromes or serious dysmorphic symptoms suggestive of a yet unknown syndrome.

Birth data were collected from medical records of hospitals, community health services and general practitioners. Information regarding SES, smoking, alcohol use, maternal smoking during gestation and presence of irregular menstrual cycle (before the start of oral contraceptive pill use (OC-use)) was obtained using questionnaires, which were answered by the participant and her mother (including questions about gestation). Menstrual regularity was defined as a menstrual cycle length of 21-35 days. Age at menarche was also determined using questionnaires. Previous research showed that recalled and actual age at menarche correlate well in young women (16). Education level of the participant was used as socioeconomic indicator to determine SES (categorised as low, medium and high; range 1-3) (17). The Medical Ethics Committee of Erasmus Medical Centre, Rotterdam, the Netherlands, approved the study. Written informed consent was obtained from all the participants.

Based on the SDS of BL and adult height, the total study group of 279 women was also divided into three subgroups. To increase the statistical power for subgroup comparison, the cut-off values for small birth size and short adult height were set at -2 SDS, and the cut-off values for normal birth size and normal adult height were set at -1 SDS. Based on these cut-off values, a total of 137 participants were included in one of the three subgroups:

- Subjects born SGA (BL $<-2$ SDS), either preterm or term, with a short adult height $(<-2$ SDS) (SGA-S): $n=31$,

- Subjects born SGA (BL $<-2$ SDS), either preterm or term, with catch-up growth resulting in a normal adult height ( $>-1$ SDS) (SGA-CU): $n=56$,

- Subjects born AGA (BL > - 1 SDS), term, with a normal adult height $(>-1$ SDS) (AGA controls): $n=50$.

To study the effect of preterm birth, women were also divided based on preterm or term birth. The preterm group comprised of women with a gestational age $<36$ weeks. The term group comprised women with a gestational age $\geq 36$ weeks.

\section{Measurements}

All the participants visited the Erasmus Medical Centre in Rotterdam. They had been fasting for at least $12 \mathrm{~h}$ and had abstained from smoking and alcohol for at least $16 \mathrm{~h}$. Height was measured to the nearest $0.1 \mathrm{~cm}$ using a Harpenden stadiometer and weight to the nearest $0.1 \mathrm{~kg}$ using scales (Servo Balance KA-20-150S). All anthropometric measurements were performed twice, and the mean value was used for analysis. All fasting blood samples were drawn between 0800 and $1300 \mathrm{~h}$ and centrifuged after clotting. Fat mass (FM) was measured on a single DXA machine (Lunar Prodigy, GE Healthcare, Chalfont St Giles, UK). Quality assurance was performed daily. The intra-assay coefficients of variation $(\mathrm{CV})$ for lean tissue and fat tissue was $1.57-4.49$ and $0.41-0.88 \%$ respectively (18). 


\section{Assays}

All samples were kept frozen $\left(-80{ }^{\circ} \mathrm{C}\right)$ until assayed. Per subject, all hormone concentrations were analysed in the same blood sample at the same laboratory. The AMH levels were measured using the Diagnostic System Laboratories (DSL) ELISA (Inc., Webster, TX, USA) (19). For 33 women, the values were adjusted $(* 3)$ because another DSL kit was used. The intra- and inter-assay CV were $<5$ and $10 \%$ respectively. In 156 of 279 subjects, serum sex hormone-binding globulin (SHBG), testosterone, non-SHBG-bound testosterone and androstenedione were additionally determined. This group consisted of 93 OC-users and 62 non-OC-users. To ensure that LH and FSH were determined during the same phase of the menstrual cycle in all participants, $\mathrm{LH}$ and FSH were only determined in women who visited the hospital during day 3-6 of the menstrual cycle $(n=21)$, or in the pill-free period in the case of OC-use $(n=78)$.

LH, FSH, SHBG and androstenedione were measured using immunometric assays (Immulite 2000, Siemens DPC, Los Angeles, CA, USA); the intra- and inter-assay CV were $<5$ and $12 \%$ for $\mathrm{LH},<3$ and $8 \%$ for FSH and $<7$ and $9 \%$ for SHBG. Testosterone was measured by coated tube RIA (Siemens DPC); the intra- and interassay CV were $<7$ and 9\%. Non-SHBG-bound testosterone was calculated using the method described by Sodergard et al. (20) using a fixed albumin level of $40 \mathrm{~g} / \mathrm{l}$. The formulas for these calculations have been previously described (21).

\section{Statistical analysis}

SDS for BL, BW, adult height and adult weight were calculated, to correct for gestational age and age (14, 15). Owing to a skewed distribution, AMH, LH, FSH, SHBG, testosterone and non-SHBG-bound testosterone were $\log$ transformed; for all $\log$ transformations, natural log was used.

The associations of birth size and gestational age with AMH levels were analysed with multiple regression modelling. BL SDS, adult height SDS and an interaction term for BL SDS and adult height SDS were added to all models because the study cohort had been selected on the basis of BL and adult height (22). This ensured that the effect of these variables was modelled correctly. For the first model, we entered age, gestational age, BW SDS (model 1). Because recent findings suggested an influence of OC-use on AMH levels, we adjusted for OC-use in model 1 (23). In the second model, we additionally corrected for FM (kg) (model 2) because obesity has been previously related to serum AMH levels (24). Thirdly, we added age at menarche to the model (model 3), and finally SES was added (model 4). We also performed multiple regression analysis to determine the effect of maternal smoking during gestation on $\mathrm{AMH}$ after correction for age, gestational age, BW SDS, OC-use, FM, age at menarche and SES.
Because maternal smoking was only known for 231 of the 279 subjects in the total group, we performed a separate analysis (model 5). Unstandardised coefficients $(\beta)$ are shown in the tables.

Smoking and alcohol use of the participants were added to the last models, but these factors had no significant effects and did not influence the results (data not shown). In addition, we performed similar stepwise regression modelling (models 1-4) using LH, FSH, SHBG, testosterone, non-SHBG-bound testosterone and androstenedione as dependent variables.

ANOVA was used to determine if there were differences between subgroups, and preterm- versus term-born women with regard to group characteristics. Post hoc Bonferroni's correction was used for pairwise group comparisons. A Kruskal-Wallis test was used to determine associations between preterm birth/ subgroup and OC-use, proportion of mothers smoking during pregnancy and SES, and to determine the association between maternal smoking during gestation and SES. To determine which subgroups differed significantly regarding SES, the Kruskal-Wallis test was performed pairwise. Subgroup comparisons were not done for LH and FSH because the sizes of the subgroups were too small. To determine differences in AMH, SHBG, testosterone, non-SHBG-bound testosterone and androstenedione levels between the subgroups, an ANCOVA model was used with AGA controls as reference group and SGA-S and SGA-CU as dummy variables, adjusted for age, OC-use and gestational age (model 1). To avoid over adjustment for gestational age in ANCOVA analysis, the AGA women born preterm were included in the AGA control group. This resulted in a total number of 76 subjects in the reference group. Stepwise additional adjustment was performed for FM (model 2), age at menarche (model 3) and SES (model 4). Maternal smoking during gestation was studied in a separate analysis (model 5). Smoking and alcohol use were added to the last models, but these factors did not influence the results of the subgroup comparisons.

Statistical package SPSS version 15.0 (SPSS, Inc., Chicago, IL, USA) was used for analysis. Results were regarded statistically significant if $P$ was $<0.05$.

\section{Results}

\section{Total study population}

Table 1 shows the clinical characteristics of the total study population. Table 2 shows unadjusted median (interquartile range) hormone levels of the total study population. The results of multiple regression analysis are shown in Table 3. Gestational age, BW SDS and BL SDS were not significantly associated with AMH levels. OC-use had an inverse association with AMH in each model $(P<0.001)$. In model 3 , age at menarche was added, which showed a significant inverse association 
Table 1 Clinical characteristics of women in the PROGRAM/PREMS study and unadjusted differences between subgroups. Values are given as mean (S.D.).

\begin{tabular}{|c|c|c|c|c|c|c|}
\hline & \multicolumn{3}{|c|}{ Study group } & \multirow[b]{2}{*}{$\begin{array}{l}\text { SGA-S } \\
(n=31)\end{array}$} & \multirow[b]{2}{*}{$\begin{array}{c}\text { SGA-CU } \\
(n=56)\end{array}$} & \multirow[b]{2}{*}{$\begin{array}{c}\text { AGA controls } \\
(n=50)\end{array}$} \\
\hline & $\begin{array}{c}\text { Total } \\
(n=279)\end{array}$ & $\begin{array}{c}\text { Preterm } \\
(n=84)\end{array}$ & $\begin{array}{c}\text { Term } \\
(n=195)\end{array}$ & & & \\
\hline BL (SDS) & $-1.5(1.6)$ & $-1.4(1.9)^{\ddagger}$ & $-1.5(1.5)$ & $-2.9(0.7)^{\ddagger}$ & $-3.0(0.9)^{\ddagger}$ & $0.06(0.8)$ \\
\hline BW (SDS) & $-1.0(1.5)$ & $-0.77(1.7)^{\star, \S}$ & $-1.2(1.4)$ & $-2.0(1.0)^{\ddagger}$ & $-2.4(0.8)^{\ddagger}$ & $-0.15(1.2)$ \\
\hline GA (weeks) & $37.0(3.8)$ & $32.0(2.3)^{\dagger, f}$ & $39.1(1.7)$ & $38.6(3.2)^{\top}$ & $35.9(3.3)^{\ddagger}$ & $39.4(1.7)$ \\
\hline Age (years) & $20.7(1.7)$ & $20.5(1.6)$ & $20.8(1.7)$ & $20.8(1.8)$ & $20.6(1.6)$ & $20.7(1.8)$ \\
\hline Height $(\mathrm{cm})$ & $165.0(8.7)$ & $167.7(6.5)^{\dagger, \neq}$ & $163.8(9.2)$ & $153.6(3.3)^{\ddagger \text {, }}$ & $169.9(4.6)$ & $173.0(6.2)$ \\
\hline Height (SDS) & $-0.84(1.3)$ & $-0.43(1.0)^{\dagger, \ddagger}$ & $-1.0(1.4)$ & $-2.6(0.5)^{\ddagger, \uparrow}$ & $-0.12(0.7)^{\|}$ & $0.41(1.0)$ \\
\hline Weight (kg) & $61.4(11.3)$ & $63.3(11.3)$ & $60.6(11.2)$ & $56.2(11.9)^{\mathrm{a}, \|}$ & $64.5(13.6)$ & $65.0(8.6)$ \\
\hline Weight (SDS) & $-0.46(1.4)$ & $-0.21(1.3)^{*}$ & $-0.57(1.4)$ & $-1.2(1.6)^{f, a}$ & $-0.10(1.3)^{\ddagger}$ & $0.10(0.94)$ \\
\hline BMI $\left(\mathrm{kg} / \mathrm{m}^{2}\right)$ & $22.6(4.0)$ & $22.5(3.9)$ & $22.6(4.0)$ & $22.5(3.3)$ & $23.8(5.0)$ & $21.7(2.7)$ \\
\hline Fat mass $(\mathrm{kg})$ & $18.9(8.5)$ & $20.5(8.5)^{*}$ & $18.2(8.5)$ & $18.8(8.8)$ & $20.0(10.8)$ & $18.3(7.5)$ \\
\hline Fat mass $(\%)$ & $30.2(8.5)$ & $31.8(7.9)^{*, \|}$ & $29.4(8.6)$ & $32.7(8.1)$ & $30.3(8.6)$ & $27.6(8.2)$ \\
\hline Age menarche (years) & $13.0(1.4)$ & $13.1(1.6)$ & $12.9(1.4)$ & $12.8(1.6)$ & $12.9(1.4)$ & $13.0(1.3)$ \\
\hline Maternal smoking (\% smokers) & 33.3 & 24.7 & 37.3 & $50.0^{\S}$ & $45.2^{\S}$ & 25.0 \\
\hline $\begin{array}{l}\text { OC-use (\% users) } \\
\text { SES (\%) }\end{array}$ & 77.0 & 72.6 & 78.9 & 64.5 & 81.8 & 74.0 \\
\hline 1 & 10.4 & 12.3 & 9.5 & 14.8 & 6.7 & 6.4 \\
\hline 2 & 25.3 & $32.9^{11}$ & 22.0 & $33.3^{\|}$ & $37.8^{\prime \prime}$ & 8.5 \\
\hline 3 & 64.3 & 54.8 & 68.5 & 51.9 & 55.6 & 85.1 \\
\hline
\end{tabular}

$\mathrm{BL}$, birth length; BW, birth weight; GA, gestational age; OC-use, oral contraceptive pill use; SES, socioeconomic status. ${ }^{*} P<0.05$ compared with term, ${ }^{\dagger} P<0.001$ compared with term, ${ }^{\ddagger} P<0.001$ compared with AGA controls, $\$ P<0.05$ compared with AGA controls, $\| P<0.01$ compared with AGA controls, ${ }^{\top} P<0.001$ compared with SGA-CU, a $P<0.05$ compared with SGA-CU.

with AMH levels $(P=0.004)$. Smoking and alcohol use of the participants were added to the last models, but these factors had no significant effects and did not influence the results. Although several parameters showed a significant influence on AMH, the adjusted $R^{2}$ remained low $\left(R^{2}=0.15\right.$ in model 4$)$.

Because maternal smoking was only known for 231 of the 279 subjects in the total group, we performed separate analyses. Multiple regression analyses showed that maternal smoking during gestation was significantly associated with higher serum AMH levels after adjustment for age, gestational age, BW SDS, OC-use, BL SDS, adult height SDS, FM, age at menarche and SES
$(P=0.022)$ (Table 3, model 5). Only after correction for maternal smoking during gestation in model 5 , SES was positively associated with AMH levels $(P=0.044)$.

Table 4 summarises the results of regression analyses, using LH, FSH, SHBG, testosterone, non-SHBG-bound testosterone and androstenedione as dependent variables. Adult height SDS was positively associated with androstenedione levels $(P=0.044)$, after correction for several factors including BL SDS and OC-use. The only other significant effect was OC-use, which had a significant effect on all parameters. Maternal smoking during gestation did not influence any of the additional parameters.

Table 2 Unadjusted hormone levels in the total group, preterm- versus term-born subjects and in the various subgroups. Subgroup comparisons were not done for $\mathrm{LH}$ and FSH because of small group sizes.

\begin{tabular}{|c|c|c|c|c|c|c|}
\hline & \multicolumn{3}{|c|}{ Study group } & \multirow[b]{2}{*}{$\begin{array}{l}\text { SGA-S } \\
(n=31)\end{array}$} & \multirow[b]{2}{*}{$\begin{array}{l}\text { SGA-CU } \\
(n=56)\end{array}$} & \multirow[b]{2}{*}{$\begin{array}{l}\text { AGA controls } \\
\qquad(n=50)\end{array}$} \\
\hline & $\begin{array}{l}\text { Total } \\
(n=279)\end{array}$ & $\begin{array}{l}\text { Preterm } \\
(n=84)\end{array}$ & $\begin{array}{c}\text { Term } \\
(n=195)\end{array}$ & & & \\
\hline $\mathrm{AMH}\left(\mu \mathrm{g} / \mathrm{l}^{\mathrm{a}, \mathrm{b}}\right.$ & $7.6(4.7-11.5)$ & $7.8(5.2-11.4)$ & $7.5(4.3-11.5)$ & $5.9(4.4-9.7)$ & $9.4(6.5-13.5)$ & $7.9(4.8-11.4)$ \\
\hline $\mathrm{LH}(\mathrm{U} / \mathrm{l})^{\mathrm{a}, \mathrm{b}, \mathrm{c}}$ & $2.5(0.50-4.9)$ & $4.7(1.9-14.6)$ & $2.4(0.40-4.7)$ & $2.8(0.43-4.6)$ & $1.6(0.10-3.1)$ & $2.7(0.20-6.0)$ \\
\hline $\mathrm{FSH}(\mathrm{U} / \mathrm{l})^{\mathrm{a}, \mathrm{b}, \mathrm{c}}$ & $5.4(1.5-7.2)$ & $7.3(6.1-11.5)$ & $5.3(1.4-7.1)$ & $6.3(3.9-7.4)$ & $3.9(0.80-6.2)$ & $4.9(0.70-6.6)$ \\
\hline SHBG $(n m o l / l)^{a, b, d}$ & $69.5(45.0-132.0)$ & $54.0(38.2-80.7)^{\star}$ & $81.1(50.4-152.0)$ & $66.4(47.7-141.0)$ & $78.7(52.7-136.5)$ & $71.3(43.4-168.0)$ \\
\hline Testosterone $(\mathrm{nmol} / \mathrm{l})^{\mathrm{a}, \mathrm{b}, \mathrm{d}}$ & $0.90(0.50-1.4)$ & $1.1(0.80-1.5)$ & $0.80(0.50-1.3)$ & $0.80(0.50-1.3)$ & $0.90(0.40-1.4)$ & $0.80(0.50-1.4)$ \\
\hline $\begin{array}{l}\text { Non-SHBG-bound } \\
\text { testosterone }(\mathrm{nmol} / /)^{\mathrm{a}, \mathrm{b}, \mathrm{d}}\end{array}$ & $0.29(0.11-1.4)$ & $0.46(0.22-0.61)^{*}$ & $0.25(0.10-0.50)$ & $0.35(0.12-0.48)$ & $0.20(0.09-0.48)$ & $0.29(0.13-0.51)$ \\
\hline Androstenedione $(\mathrm{nmol} / /)^{\mathrm{a}, \mathrm{d}}$ & $8.2(5.8-10.8)$ & $10.2(7.5-11.9)^{\star}$ & $8.0(5.3-10.3)$ & $8.1(6.4-10.5)$ & $7.7(5.0-11.3)$ & $8.3(5.3-10.5)$ \\
\hline
\end{tabular}

AMH, anti-Müllerian hormone; SHBG, sex hormone-binding globulin. ${ }^{*} P<0.05$ compared with term.

${ }^{a}$ Values are given as median (interquartile range).

${ }^{b}$ Log transformed for ANOVA.

cOnly determined during day 3-6 of the menstrual cycle $(n=21)$ or in the pill-free period in case of OC-use $(n=78)$.

${ }^{\mathrm{d}} \mathrm{SHBG}$, testosterone and A were determined in a subset of 157 females. 
Table 3 Multiple regression analysis of factors that influence serum anti-Müllerian hormone (AMH) levels $(\mu \mathrm{g} / \mathrm{l})$ in young women. AMH is log transformed. A $\beta$ value of $0.50,0.10$ and 0.01 equals an increase in $\mathrm{AMH}$ of $64.8,10.5$ and $1.01 \%$ per unit change of the independent variable respectively. Model 1 includes age, gestational age, birth weight SDS, birth length SDS, oral contraceptive pill use (OC-use), adult height SDS and an interaction term for birth length SDS and adult height SDS. Model 2 additionally includes fat mass. Model 3 additionally includes age at menarche. Model 4 additionally includes socioeconomic status (SES). Model 5 additionally includes maternal smoking during gestation.

\begin{tabular}{|c|c|c|c|c|c|c|c|c|c|c|}
\hline & \multicolumn{2}{|c|}{ Model 1} & \multicolumn{2}{|c|}{ Model 2} & \multicolumn{2}{|c|}{ Model 3} & \multicolumn{2}{|c|}{ Model 4} & \multicolumn{2}{|c|}{ Model $5^{a}$} \\
\hline & $\beta$ & $P$ value & $\beta$ & $P$ value & $\beta$ & $P$ value & $\beta$ & $P$ value & $\beta$ & $P$ value \\
\hline GA (weeks) & -0.006 & 0.675 & -0.004 & 0.805 & -0.002 & 0.893 & -0.006 & 0.654 & -0.008 & 0.561 \\
\hline Birth weight SDS & -0.091 & 0.073 & -0.087 & 0.088 & -0.075 & 0.134 & -0.083 & 0.098 & -0.080 & 0.114 \\
\hline Birth length SDS & 0.038 & 0.456 & 0.033 & 0.533 & 0.021 & 0.684 & 0.020 & 0.639 & 0.022 & 0.670 \\
\hline OC-use & -0.579 & $<0.001$ & -0.576 & $<0.001$ & -0.576 & $<\mathbf{0 . 0 0 1}$ & -0.564 & $<0.001$ & -0.592 & $<0.001$ \\
\hline Adult height SDS & -0.024 & 0.628 & -0.026 & 0.594 & -0.017 & 0.718 & -0.029 & 0.549 & -0.025 & 0.617 \\
\hline Fat mass $(\mathrm{kg})$ & & & 0.006 & 0.359 & 0.000 & 0.951 & 0.001 & 0.817 & 0.002 & 0.760 \\
\hline Age at menarche (years) & & & & & -0.105 & 0.004 & -0.107 & 0.003 & -0.104 & 0.005 \\
\hline SESS & & & & & & & 0.125 & 0.093 & 0.158 & 0.044 \\
\hline Maternal smoking & & & & & & & & & 0.255 & 0.022 \\
\hline Overall $P$ value & & $<0.001$ & & $<0.001$ & & $<0.001$ & & $<0.001$ & & $<0.001$ \\
\hline Adjusted $R^{2}$ & & 0.11 & & 0.11 & & 0.14 & & 0.15 & & 0.18 \\
\hline
\end{tabular}

OC-use, oral contraceptive use $(1=$ yes $0=$ no); GA, gestational age; SES, socioeconomic status. Maternal smoking: $1=$ yes, $0=$ no.

${ }^{a}$ Maternal smoking was known in 231 of 279 women.

Values in boldface indicate $P<0.05$.

\section{Subgroup comparisons}

Clinical characteristics of the subgroups are shown in Table 1. Women born preterm had a higher BW SDS $(P=0.043)$ and adult height SDS $(P<0.001)$ than those born term. Furthermore, their mean weight SDS $(P=0.046)$, percentage FM $(P=0.030)$ and FM $(\mathrm{kg})$ $(P=0.038)$ were higher. The difference in SES between preterm- and term-born women was borderline significant $(P=0.054)$. Women born preterm had a lower adult height (height $(\mathrm{cm}): P<0.001)$ and height SDS: $P<0.001)$, a higher percentage FM than AGA controls (FM (\%): $P=0.004)$ and a lower BW SDS $(P=0.037)$. The SES of AGA controls was higher than that of women born preterm $(P=0.002)$.

In agreement with selection criteria, significant differences were observed between SGA-S, SGA-CU women and AGA controls in gestational age, BL SDS, BW SDS, height and height SDS. Mean gestational age of SGA-CU women was lower than that of SGA-S $(P<0.001)$ women. SGA-S $(P=0.003)$ and SGA-CU $(P=0.004)$ women had a lower SES than AGA controls. There were no significant differences between subgroups regarding age at menarche and proportion of OC-use. In both SGA subgroups (SGA-S and SGA-CU), the prevalence of maternal smoking during gestation was higher than in the AGA control group $(P=0.035$ and $P=0.050$ respectively). Furthermore, lower SES was associated with a higher proportion of mothers smoking during gestation $(P<0.001)$.

Table 2 shows median (interquartile range) serum hormone levels of the women in the PROGRAM/PREMS study divided in subgroups. Preterm- and term-born subjects had similar AMH levels, also after adjustment for BL SDS, adult height SDS, BW SDS, age, OC-use, FM, age at menarche and SES. Preterm-born women had higher non-SHBG-bound testosterone levels $(P=0.030)$ and androstenedione levels $(P=0.012)$, and lower SHBG levels $(P=0.013)$ than term-born women. However, there were no significant differences in serum hormone levels between women born preterm and AGA controls.

SGA-CU women had the highest median AMH levels, but this difference did not reach significance (Table 2). The women in the SGA-S and SGA-CU subgroups more often reported an irregular menstrual cycle (before the start of OC-use) than AGA controls $(P=0.016$ and $P=0.003$ respectively).

After adjustment for age, gestational age and OC-use, subgroup comparisons revealed significantly higher AMH levels in SGA-CU women than in AGA controls (Table 5: $P=0.029$ ). This difference remained significant after stepwise additional adjustment for FM, age at menarche and SES $(P=0.030, P=0.026$ and $P=0.019$ respectively). Additional adjustment for maternal smoking during gestation and smoking or alcohol use did not influence these results. Comparison of SGA-S and SGA-CU with AGA controls revealed no differences in SHBG, testosterone, non-SHBG-bound testosterone and androstenedione levels. Also after correction for age, OC-use, gestational age, FM, age at menarche, SES and maternal smoking during gestation, no significant differences could be established between subgroups.

\section{Discussion}

This is the first study to investigate the influence of preterm and SGA birth on AMH levels in young women. There were no adverse effects of preterm and SGA birth on AMH levels, a good proxy for the size of the ovarian follicle pool (9-11), and on other gonadal function parameters.

Older age at menarche and $\mathrm{OC}$-use were related to lower AMH levels. Maternal smoking during gestation 
Table 4 Multiple regression analysis of factors that influence on sex hormone-binding globulin (SHBG), testosterone, non-SHBG-bound testosterone and androstenedione. Adjusted for age and an interaction term for birth length SDS and adult height SDS.

\begin{tabular}{|c|c|c|c|c|c|c|c|c|c|c|}
\hline & \multicolumn{2}{|c|}{$\mathbf{L H}(\mathrm{U} / \mathrm{l})^{\mathrm{a}, \mathrm{b}}$} & \multicolumn{2}{|c|}{ SHBG $(\mathrm{nmol} / \mathrm{l})^{\mathrm{a}, \mathrm{c}}$} & \multicolumn{2}{|c|}{$\begin{array}{l}\text { Testosterone } \\
(\mathrm{nmol} / \mathrm{l})^{\mathrm{a}, \mathrm{c}}\end{array}$} & \multicolumn{2}{|c|}{$\begin{array}{l}\text { Non-SHBG-bound } \\
\text { testosterone } \\
(\mathrm{nmol} / \mathrm{l})^{\mathrm{a}, \mathrm{c}}\end{array}$} & \multicolumn{2}{|c|}{$\begin{array}{l}\text { Androstenedione } \\
\qquad(\mathrm{nmol} / \mathrm{l})^{\mathrm{C}}\end{array}$} \\
\hline & $\beta$ & $P$ value & $\beta$ & $P$ value & $\beta$ & $P$ value & $\beta$ & $P$ value & $\beta$ & $P$ value \\
\hline GA (weeks) & -0.096 & 0.274 & 0.024 & 0.105 & -0.019 & 0.357 & -0.035 & 0.103 & -0.103 & 0.323 \\
\hline Birth weight SDS & 0.037 & 0.870 & -0.063 & 0.238 & 0.081 & 0.305 & 0.031 & 0.697 & -0.093 & 0.810 \\
\hline Birth length SDS & 0.177 & 0.391 & 0.034 & 0.505 & -0.047 & 0.521 & 0.033 & 0.654 & 0.096 & 0.790 \\
\hline OC-use & -1.278 & 0.007 & 1.025 & $<0.001$ & -0.720 & $<0.001$ & -1.386 & $<0.001$ & -3.899 & $<\mathbf{0 . 0 0 1}$ \\
\hline Adult height SDS & 0.110 & 0.571 & -0.058 & 0.258 & 0.097 & 0.177 & 0.139 & 0.067 & 0.750 & 0.044 \\
\hline Fat mass $(\mathrm{kg})$ & 0.037 & 0.129 & 0.000 & 0.958 & 0.004 & 0.682 & 0.000 & 0.987 & -0.013 & 0.764 \\
\hline Age at menarche (years) & 0.017 & 0.910 & 0.035 & 0.331 & -0.058 & 0.252 & -0.102 & 0.057 & -0.251 & 0.335 \\
\hline SES & -0.227 & 0.361 & -0.032 & 0.644 & 0.021 & 0.825 & 0.056 & 0.578 & -0.409 & 0.407 \\
\hline Overall $P$ value & & 0.054 & & $<0.001$ & & $<0.001$ & & $<0.001$ & & $<0.001$ \\
\hline Adjusted $R^{2}$ & & 0.11 & & 0.52 & & 0.24 & & 0.51 & & 0.24 \\
\hline
\end{tabular}

OC-use, oral contraceptive use $(1=$ yes $0=$ no); GA, gestational age; OC-use, oral contraceptive pill use; SES, socioeconomic status. The model with FSH as dependent variable is not shown (overall $P$ value was 0.220 ).

aLog transformed.

${ }^{\mathrm{b}}$ Only determined during day 3-6 of the menses $(n=21)$ or in the pill-free period in the case of OC-use $(n=78)$. Subgroup comparisons were not done for $\mathrm{LH}$ and FSH.

${ }^{\mathrm{C}} \mathrm{SHBG}$, testosterone and A were determined in a number of 157 females.

Values in boldface indicate $P<0.05$.

was related to higher AMH levels, after correction for SES, whereas lower SES was associated with lower AMH levels. Subgroup comparison showed higher AMH levels in SGA-CU women than in AGA controls, also after adjustment for several factors including gestational age.

Our study demonstrates that preterm and SGA birth did not affect serum AMH levels, and therefore the size of the ovarian follicle pool in young adulthood. Previously, an association was found between preterm birth and a reduced reproduction rate (5). Unfortunately, that study did not investigate serum AMH levels. From the present study, we can conclude that this was unlikely caused by a reduced primordial follicle pool count. An effect of gestational age on FSH and LH levels in infants born preterm has also been reported $(25,26)$, but this had never been studied in adult women. Our study shows that gestational age does neither affect FSH nor LH levels in young women. This is in line with our study in young men that showed no effect of preterm birth on FSH and LH levels (6).

Notably, OC-use was associated with lower AMH levels. Controversies exist with regard to the effect of OC-use on serum AMH levels. Some studies showed that exogenous sex steroids did not affect AMH levels (27), whereas others did find an effect of OC-use $(23,28)$. In our study, the effect of OC-use on AMH levels remained significant, even after stepwise correction for age, gestational age, BL SDS, BW SDS, adult height SDS, FM, age at menarche, SES, smoking, alcohol use and maternal smoking during gestation. Recently, it has been suggested that variation in $\mathrm{AMH}$ levels during the normal menstrual cycle and during OC-use is most pronounced in young women. This might also account for the obvious differences between the current study and previous reports (13).

We found a significant inverse association between age at menarche and AMH levels in young women, also after correction for several factors. One explanation might be that women with earlier age at menarche have a larger ovarian follicle pool which might enhance the chance of achieving higher oestrogen levels earlier than those with a smaller follicular pool. Research showed that increased oestrogen levels may promote the onset of the first menstrual bleeding (29). Maternal smoking during gestation was also associated with higher AMH levels in

Table 5 Subgroup comparisons of anti-Müllerian hormone (AMH) levels ( $\mu$ g/l). Appropriate for gestational age (AGA) controls are used as reference group. AMH is log transformed. Model 1 is corrected for age, oral contraceptive pill use (OC-use) and gestational age. Model 2 is additionally corrected for fat mass $(\mathrm{kg})$. Model 3 is additionally corrected for age at menarche. Model 4 is additionally corrected for socioeconomic status (SES). Model 5 additionally includes maternal smoking during gestation.

\begin{tabular}{|c|c|c|c|c|c|c|c|c|c|c|}
\hline & \multicolumn{2}{|c|}{ Model 1} & \multicolumn{2}{|c|}{ Model 2} & \multicolumn{2}{|c|}{ Model 3} & \multicolumn{2}{|c|}{ Model 4} & \multicolumn{2}{|c|}{ Model $5^{a}$} \\
\hline & $\beta$ & $P$ value & $\beta$ & $P$ value & $\beta$ & $P$ value & $\beta$ & $P$ value & $\beta$ & $P$ value \\
\hline $\begin{array}{l}\text { SGA-S } \\
\text { SGA-CU } \\
\text { Overall } P \text { value } \\
\text { Adjusted } R^{2}\end{array}$ & $\begin{array}{r}-0.24 \\
0.33\end{array}$ & $\begin{array}{r}0.159 \\
\mathbf{0 . 0 2 9} \\
<\mathbf{0 . 0 0 1} \\
0.15\end{array}$ & $\begin{array}{r}-0.24 \\
0.33\end{array}$ & $\begin{array}{r}0.161 \\
\mathbf{0 . 0 3 0} \\
<\mathbf{0 . 0 0 1} \\
0.14\end{array}$ & $\begin{array}{r}-0.26 \\
0.33\end{array}$ & $\begin{array}{r}0.123 \\
\mathbf{0 . 0 2 6} \\
<\mathbf{0 . 0 0 1} \\
0.19\end{array}$ & $\begin{array}{r}-0.23 \\
0.35\end{array}$ & $\begin{array}{r}0.190 \\
\mathbf{0 . 0 1 9} \\
<\mathbf{0 . 0 0 1} \\
0.19\end{array}$ & $\begin{array}{r}-0.31 \\
0.34\end{array}$ & $\begin{array}{r}0.081 \\
\mathbf{0 . 0 3 3} \\
<\mathbf{0 . 0 0 1} \\
0.21\end{array}$ \\
\hline
\end{tabular}

aSeparately analysed, maternal smoking during gestation was known for 26 SGA-S, 42 SGA-CU and 68 control women.

Values in boldface indicate $P<0.05$. 
young women. Recently, it was shown in adolescent girls that maternal smoking during gestation is associated with a reduced uterus size. That study did not show an effect of maternal smoking during gestation on serum AMH levels (30). However, the investigators did not correct their analyses for SES, which had significant influence in our study after correction for maternal smoking during gestation. Because a lower SES is related to maternal smoking during gestation and maternal smoking during gestation and lower SES have opposite effects on AMH, it is important to adjust for SES when studying the effect of maternal smoking during gestation on AMH levels.

After correction for maternal smoking and several other factors, lower SES was significantly associated with lower AMH levels. This might indicate that women with a lower SES have a smaller follicle pool than those with a higher SES. These data are in line with our findings in males. We previously showed that a lower SES was associated with lower inhibin B and higher FSH levels in young men (6). An explanation of the relationship between SES and gonadal function in females and males could be that there are nutritional and environmental differences due to SES. Endocrine disrupters have been shown to affect pubertal development, and subjects with a lower SES might be more exposed to endocrine disrupters, for example by inadequate food consumption $(31,32)$.

Recently, it was shown that both low- and high-BW infants had higher AMH levels than normal BW infants (33). In that study, a link was suggested between IUGR and polycystic ovary syndrome (PCOS), possibly caused by intrauterine programming affecting reproduction function in low-BW infant girls. Another explanation could be the positive relationship between insulin and $\mathrm{AMH}$, as high-BW infants as well as low-BW infants who show catch-up growth are likely to have high insulin levels $(33,34)$. Other recent studies showed no relation of BW with PCOS and AMH levels (30, 35). Unfortunately, in these studies no distinction was made for infants with and without catch-up growth.

In our study, the SGA-CU subgroup showed significantly higher AMH levels than AGA controls, also after adjustment for several factors including SES and maternal smoking during gestation. Furthermore, the women in the SGA-S and SGA-CU subgroups more often reported an irregular menstrual cycle than those in the AGA control subgroup. This finding should not be interpreted rigidly, as we used questionnaires to assess menstrual irregularity, and the participants who used oral contraceptives had to remember their menstrual cycle before the start of OC-use. However, as increased serum AMH levels and irregular menstrual cycle are both associated with PCOS (8), our findings in the SGA-CU group might suggest that a larger proportion of women born SGA with catch-up growth have early signs of PCOS. This is in line with a study in sheep demonstrating a PCOS-like phenotype in sheep that gained a lot of weight postnatally (36). Furthermore, women with PCOS, as well as SGA-CU women, have decreased insulin sensitivity $(8,37)$. The hypothesis that SGA-CU women might have an increased chance to develop PCOS is not supported by the finding that SGA-CU women in the present study had similar testosterone and androstenedione levels as controls, after correction for confounders. As our study was not designed to investigate PCOS, we cannot draw definitive conclusions from these findings.

In conclusion, our study in 279 young women shows that preterm and SGA birth do not affect AMH levels. Catch-up growth after SGA birth might, however, be associated with increased AMH levels. Other factors associated with serum AMH levels were OC-use, age at menarche, maternal smoking during gestation and SES. Our results suggest that women born preterm and/or SGA do not have a smaller follicle pool size than women born at term and/or AGA, obviating the need for extra monitoring of ovarian function in these women.

\section{Declaration of interest}

The authors declare that there is no conflict of interest that could be perceived as prejudicing the impartiality of the research reported.

\section{Funding}

The PROGRAM study was financially supported by the Netherlands Organization for Scientific Research (NWO) (ACSHK received the ASPASIA award (grant number 015000 088)), by grants from Revolving Fund 2001 and Vereniging Trustfonds, Erasmus University Rotterdam and a grant by the Jan Dekkerstichting/Dr Ludgardine Bouwmanstichting and Stichting De Drie Lichten, The Netherlands.

\section{Acknowledgements}

We greatly thank Mrs J Dunk, research nurse. We acknowledge Mrs J Sluimer for checking DXA results.

\section{References}

1 Ibanez L, Potau N, Enriquez G \& de Zegher F. Reduced uterine and ovarian size in adolescent girls born small for gestational age. Pediatric Research 200047 575-577. (doi:10.1203/00006450200005000-00003)

2 Ibanez L, Potau N, Enriquez G, Marcos MV \& de Zegher F. Hypergonadotrophinaemia with reduced uterine and ovarian size in women born small-for-gestational-age. Human Reproduction 200318 1565-1569. (doi:10.1093/humrep/deg351)

3 Hernandez MI, Martinez A, Capurro T, Pena V, Trejo L, Avila A, Salazar T, Asenjo S, Iniguez G \& Mericq V. Comparison of clinical, ultrasonographic, and biochemical differences at the beginning of puberty in healthy girls born either small for gestational age or appropriate for gestational age: preliminary results. Journal of Clinical Endocrinology and Metabolism 200691 3377-3381. (doi:10.1210/jc.2005-2368)

4 de Bruin JP, Nikkels PG, Bruinse HW, van Haaften M, Looman CW \& te Velde ER. Morphometry of human ovaries in normal and growth-restricted fetuses. Early Human Development 200160 179-192. (doi:10.1016/S0378-3782(00)00118-3)

5 Swamy GK, Ostbye T \& Skjaerven R. Association of preterm birth with long-term survival, reproduction, and next-generation preterm birth. Journal of the American Medical Association 2008 299 1429-1436. (doi:10.1001/jama.299.12.1429)

6 Kerkhof GF, Leunissen RW, Willemsen RH, de Jong FH, Stijnen T \& Hokken-Koelega AC. Influence of preterm birth and birth size on gonadal function in young men. Journal of Clinical Endocrinology and Metabolism 2009 94 4243-4250. (doi:10.1210/jc.2009-1036) 
7 Fowden AL, Giussani DA \& Forhead AJ. Endocrine and metabolic programming during intrauterine development. Early Human Development 200581 723-734. (doi:10.1016/j.earlhumdev.2005.06.007)

8 La Marca A, Broekmans FJ, Volpe A, Fauser BC, Macklon NS \& Table ESIGfRE-AR. Anti-Müllerian hormone (AMH): what do we still need to know? Human Reproduction $2009242264-2275$. (doi:10.1093/humrep/dep210)

9 de Vet A, Laven JS, de Jong FH, Themmen AP \& Fauser BC. Anti-Müllerian hormone serum levels: a putative marker for ovarian aging. Fertility and Sterility 200277 357-362. (doi:10. 1016/S0015-0282(01)02993-4)

10 van Rooij IA, Broekmans FJ, te Velde ER, Fauser BC, Bancsi LF, de Jong FH \& Themmen AP. Serum anti-Müllerian hormone levels: a novel measure of ovarian reserve. Human Reproduction 200217 3065-3071. (doi:10.1093/humrep/17.12.3065)

11 Kwee J, Schats R, McDonnell J, Themmen A, de Jong F \& Lambalk C. Evaluation of anti-Müllerian hormone as a test for the prediction of ovarian reserve. Fertility and Sterility 200890 737-743. (doi:10.1016/j.fertnstert.2007.07.1293)

12 Hehenkamp WJ, Looman CW, Themmen AP, de Jong FH, Te Velde ER \& Broekmans FJ. Anti-Müllerian hormone levels in the spontaneous menstrual cycle do not show substantial fluctuation. Journal of Clinical Endocrinology and Metabolism 2006 91 4057-4063. (doi:10.1210/jc.2006-0331)

13 Sowers M, McConnell D, Gast K, Zheng H, Nan B, McCarthy JD \& Randolph JF. Anti-Müllerian hormone and inhibin B variability during normal menstrual cycles. Fertility and Sterility $2010 \mathbf{9 4}$ 1482-1486. (doi:10.1016/j.fertnstert.2009.07.1674)

14 Usher R \& McLean F. Intrauterine growth of live-born Caucasian infants at sea level: standards obtained from measurements in 7 dimensions of infants born between 25 and 44 weeks of gestation. Journal of Pediatrics $1969 \mathbf{7 4}$ 901-910. (doi:10.1016/S00223476(69)80224-6)

15 Fredriks AM, van Buuren S, Burgmeijer RJ, Meulmeester JF, Beuker RJ, Brugman E, Roede MJ, Verloove-Vanhorick SP \& Wit JM. Continuing positive secular growth change in The Netherlands 1955-1997. Pediatric Research 200047 316-323. (doi:10.1203/00006450-200003000-00006)

16 Koprowski C, Coates RJ \& Bernstein L. Ability of young women to recall past body size and age at menarche. Obesity Research 20019 478-485. (doi:10.1038/oby.2001.62)

17 Dutch Standard Classification of Education 2006 Centraal Bureau van de Statistiek, Statistics Netherlands. www.cbs.nl/en-GB

18 Guo Y, Franks PW, Brookshire T \& Antonio Tataranni P. The intraand inter-instrument reliability of DXA based on ex vivo soft tissue measurements. Obesity Research 200412 1925-1929. (doi:10.1038/oby.2004.241)

19 Kevenaar ME, Meerasahib MF, Kramer P, van de Lang-Born BM, de Jong FH, Groome NP, Themmen AP \& Visser JA. Serum anti-Müllerian hormone levels reflect the size of the primordial follicle pool in mice. Endocrinology 2006147 3228-3234. (doi:10.1210/en.2005-1588)

20 Sodergard R, Backstrom T, Shanbhag V \& Carstensen H. Calculation of free and bound fractions of testosterone and estradiol-17 beta to human plasma proteins at body temperature. Journal of Steroid Biochemistry 198216 801-810. (doi:10.1016/0022-4731(82)90038-3)

21 de Ronde W, van der Schouw YT, Muller M, Grobbee DE, Gooren LJ, Pols HA \& de Jong FH. Associations of sex-hormone-binding globulin (SHBG) with non-SHBG-bound levels of testosterone and estradiol in independently living men. Journal of Clinical Endocrinology and Metabolism 2005 90 157-162. (doi:10.1210/jc.2004-0422)

22 Willemsen RH, Leunissen RW, Stijnen T \& Hokken-Koelega AC. Prematurity is not associated with reduced insulin sensitivity in adulthood. Journal of Clinical Endocrinology and Metabolism 2009 94 1695-1700. (doi:10.1210/jc.2008-1769)

23 van den Berg MH, van Dulmen-den Broeder E, Overbeek A, Twisk JW, Schats R, van Leeuwen FE, Kaspers GJ \& Lambalk CB. Comparison of ovarian function markers in users of hormonal contraceptives during the hormone-free interval and subsequent natural early follicular phases. Human Reproduction $2010 \mathbf{2 5}$ 1520-1527. (doi:10.1093/humrep/deq071)
24 Steiner AZ, Stanczyk FZ, Patel S \& Edelman A. Anti-Müllerian hormone and obesity: insights in oral contraceptive users. Contraception 201081 245-248. (doi:10.1016/j.contraception.2009.10.004)

25 Massa G, de Zegher F \& Vanderschueren-Lodeweyckx M. Serum levels of immunoreactive inhibin, FSH, and $\mathrm{LH}$ in human infants at preterm and term birth. Biology of the Neonate 1992 61 150-155. (doi:10.1159/000243737)

26 Shinkawa O, Furuhashi N, Fukaya T, Suzuki M, Kono H \& Tachibana Y. Changes of serum gonadotropin levels and sex differences in premature and mature infant during neonatal life. Journal of Clinical Endocrinology and Metabolism $1983 \mathbf{5 6}$ 1327-1331. (doi:10.1210/jcem-56-6-1327)

27 Streuli I, Fraisse T, Pillet C, Ibecheole V, Bischof P \& de Ziegler D. Serum anti-Müllerian hormone levels remain stable throughout the menstrual cycle and after oral or vaginal administration of synthetic sex steroids. Fertility and Sterility 200890 395-400. (doi:10.1016/j.fertnstert.2007.06.023)

28 Arbo E, Vetori DV, Jimenez MF, Freitas FM, Lemos N \& CunhaFilho JS. Serum anti-Müllerian hormone levels and follicular cohort characteristics after pituitary suppression in the late luteal phase with oral contraceptive pills. Human Reproduction 200722 3192-3196. (doi:10.1093/humrep/dem258)

29 Emaus E, Espetvedt S, Veierod MB, Ballard-Barbash R, Furberg AS, Ellison PT, Jasienska G, Hjartaker A \& Thune I. 17- $\beta$-Estradiol in relation to age at menarche and adult obesity in premenopausal women. Human Reproduction 200823 919-927. (doi:10.1093/ humrep/dem432)

30 Hart R, Sloboda DM, Doherty DA, Norman RJ, Atkinson HC, Newnham JP, Dickinson JE \& Hickey M. Prenatal determinants of uterine volume and ovarian reserve in adolescence. Journal of Clinical Endocrinology and Metabolism $2009 \mathbf{9 4} 4931-4937$. (doi:10.1210/jc.2009-1342)

31 Schoeters G, Den Hond E, Dhooge W, van Larebeke N \& Leijs M. Endocrine disruptors and abnormalities of pubertal development. Basic Clinical Pharmacology \& Toxicology 2008102 168-175. (doi:10.1111/j.1742-7843.2007.00180.x)

32 Wolff MS, Britton JA, Boguski L, Hochman S, Maloney N, Serra N, Liu Z, Berkowitz G, Larson S \& Forman J. Environmental exposures and puberty in inner-city girls. Environmental Research 2008107 393-400. (doi:10.1016/j.envres.2008.03.006)

33 Sir-Petermann T, Marquez L, Carcamo M, Hitschfeld C, Codner E, Maliqueo M, Echiburu B, Aranda P, Crisosto N \& Cassorla F. Effects of birth weight on anti-Müllerian hormone serum concentrations in infant girls. Journal of Clinical Endocrinology and Metabolism 201095 903-910. (doi:10.1210/jc.2009-1771)

34 Iniguez G, Ong K, Bazaes R, Avila A, Salazar T, Dunger D \& Mericq V. Longitudinal changes in insulin-like growth factor-I, insulin sensitivity, and secretion from birth to age three years in smallfor-gestational-age children. Journal of Clinical Endocrinology and Metabolism 2006 91 4645-4649. (doi:10.1210/jc.2006-0844)

35 Legro RS, Roller RL, Dodson WC, Stetter CM, Kunselman AR \& Dunaif A. Associations of birth weight and gestational age with reproductive and metabolic phenotypes in women with polycystic ovarian syndrome and their first-degree relatives. Journal of Clinical Endocrinology and Metabolism 2010 95 789-799. (doi:10.1210/ jc.2009-1849)

36 Padmanabhan V, Veiga-Lopez A, Abbott DH, Recabarren SE \& Herkimer C. Developmental programming: impact of prenatal testosterone excess and postnatal weight gain on insulin sensitivity index and transfer of traits to offspring of overweight females. Endocrinology 2010 151 595-605. (doi:10.1210/en.2009-1015)

37 Leunissen RW, Oosterbeek P, Hol LK, Hellingman AA, Stijnen T \& Hokken-Koelega AC. Fat mass accumulation during childhood determines insulin sensitivity in early adulthood. Journal of Clinical Endocrinology and Metabolism 200893 445-451. (doi:10.1210/ jc.2007-1543)

Received 27 September 2010

Accepted 1 October 2010 